\title{
A New High-Speed X-ray Beam Chopper*
}

\author{
Armon McPherson, Jin Wang, Peter L. Lee, and Dennis M. Mills \\ Advanced Photon Source, \\ Argonne National Laboratory, Argonne, IL 60439
}

October 1999

The submitted manuscript has been created by
the University of Chicago as Operator of
Argonne National Laboratory ("Argonne") under
Contract No. W-31-109-ENG-38 with the U.S.
Department of Energy. The U.S. Government
retains for itself, and others acting on its behalf,
a paid-up, nonexclusive, irrevocable worldwide
license in said article to reproduce, prepare
derivative works, distribute copies to the public,
and perform publicly and display publicly, by
or on behalf of the Government.

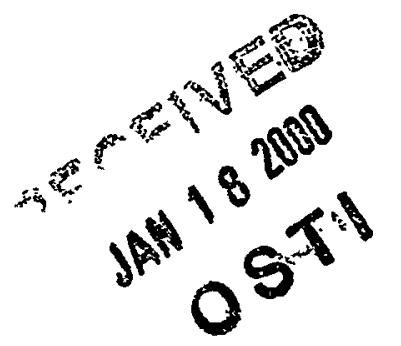

To be published in the Proceedings of the $11^{\text {th }}$ U.S. National Synchrotron Radiation Instrumentation Conference (SRI'99), Stanford, CA, October 13-15, 1999.

\footnotetext{
*This work is supported by the U.S. Department of Energy, Basic Energy Sciences, Office of Science, under contract \#W-31-109-ENG-38.
} 


\section{DISCLAIMER}

This report was prepared as an account of work sponsored by an agency of the United States Government. Neither the United States Government nor any agency thereof, nor any of their employees, make any warranty, express or implied, or assumes any legal liability or responsibility for the accuracy, completeness, or usefulness of any information, apparatus, product, or process disclosed, or represents that its use would not infringe privately owned rights. Reference herein to any specific commercial product, process, or service by trade name, trademark, manufacturer, or otherwise does not necessarily constitute or imply its endorsement, recommendation, or favoring by the United States Government or any agency thereof. The views and opinions of authors expressed herein do not necessarily state or reflect those of the United States Government or any agency thereof. 


\section{DISCLAIMER}

Portions of this document may be illegible in electronic image products. Images are produced from the best available original document. 


\title{
A New High-Speed X-ray Beam Chopper
}

\author{
Armon McPherson, Jin Wang, Peter L. Lee, and Dennis M. Mills
}

Advanced Photon Source, Argonne National Laboratory

9700 S. Cass Avenue

Argonne, Illinois 60439-4800

A new high-speed $\mathrm{x}$-ray beam chopper using laser scanner technology has been developed and tested on the SRI-CAT sector 1 beamline at the Advanced Photon Source (APS) storage ring (1). As illustrated in figure 1, it is compact in size and has two sets of transmission windows: BK-7 glass for visible light transmission and 0.23$\mathrm{mm}$-thick $\mathrm{Be}$ for the transmission of $\mathrm{x}$-rays. The rotor is made of aluminum and has a diameter of $50.8 \mathrm{~mm}$. A $0.5-\mathrm{mm}$-wide and $2.29-\mathrm{mm}$-tall slit is cut through the center

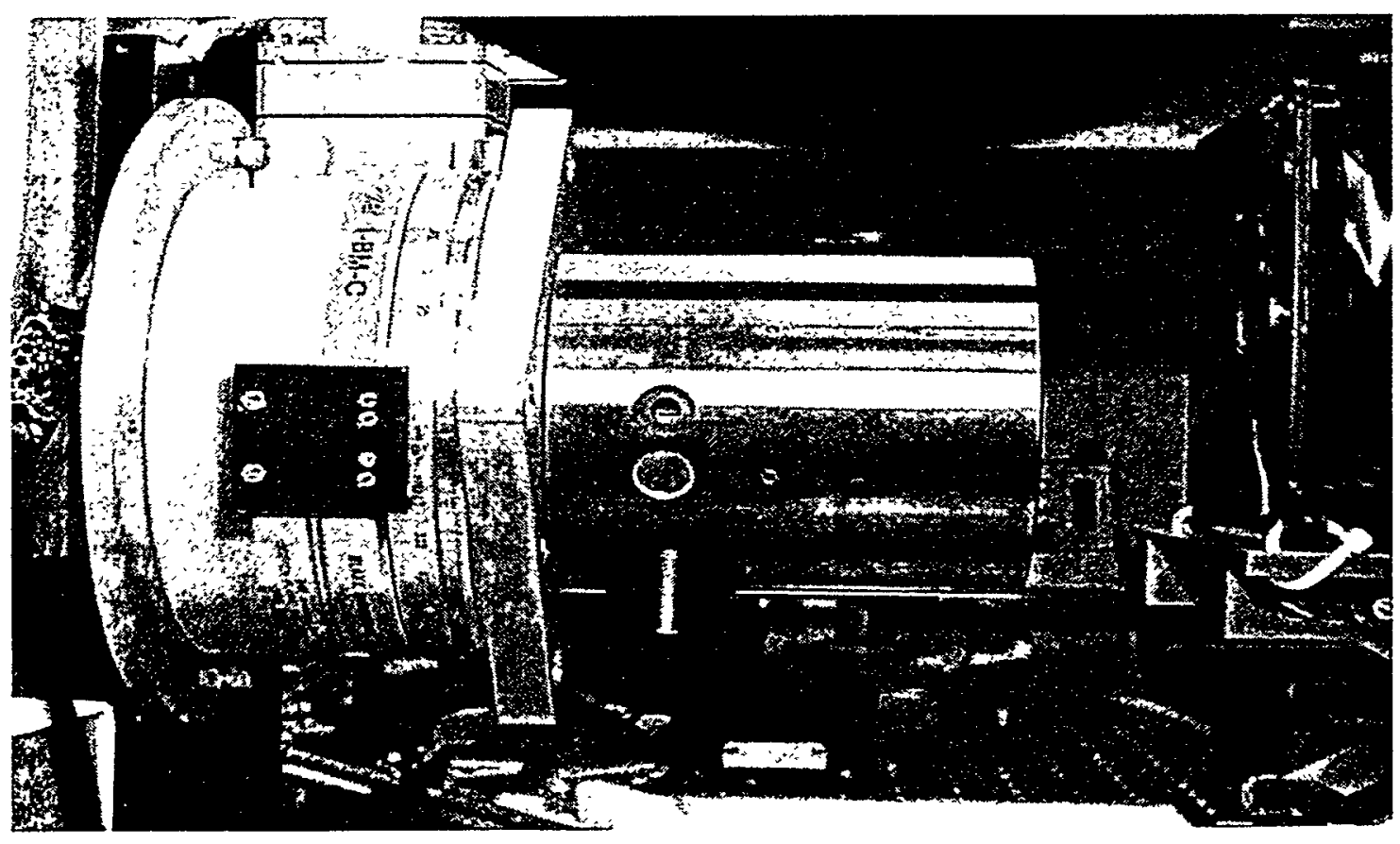

Figure 1. High-speed beam chopper mounted in the horizontal position. It may be operated in any orientation. 
of the rotor. The circumference of the rotor has a coating of 1 -mm-thick $\mathrm{Ni}$, which gives an attenuation of $10^{8}$ at $30 \mathrm{keV}$. Turning at nearly $80000 \mathrm{RPM}$, this beam chopper has an opening time window of $2450 \mathrm{~ns}$, corresponding to $67 \%$ of the revolution time of the APS storage ring. The primary feature in selecting laser scanner technology to develop into an x-ray beam chopper was the high level of rotational speed control of the rotor that makes up the beam chopper element (2). By using an optical feedback circuit to sample the rotational speed four times each revolution, the jitter in the position of the transmission open time window is only $3 \mathrm{~ns}$ at the 3 standard deviation level. The APS storage ring orbital frequency, supplied by the control room, is divided down to provide the appropriate drive frequency for the beam chopper motor controller. By this means, both the storage ring and the beam chopper are operating off the same master clock. After a turn-on time of about 15 to 20 seconds, the rotational precision of the motor results in immediate phase locking to

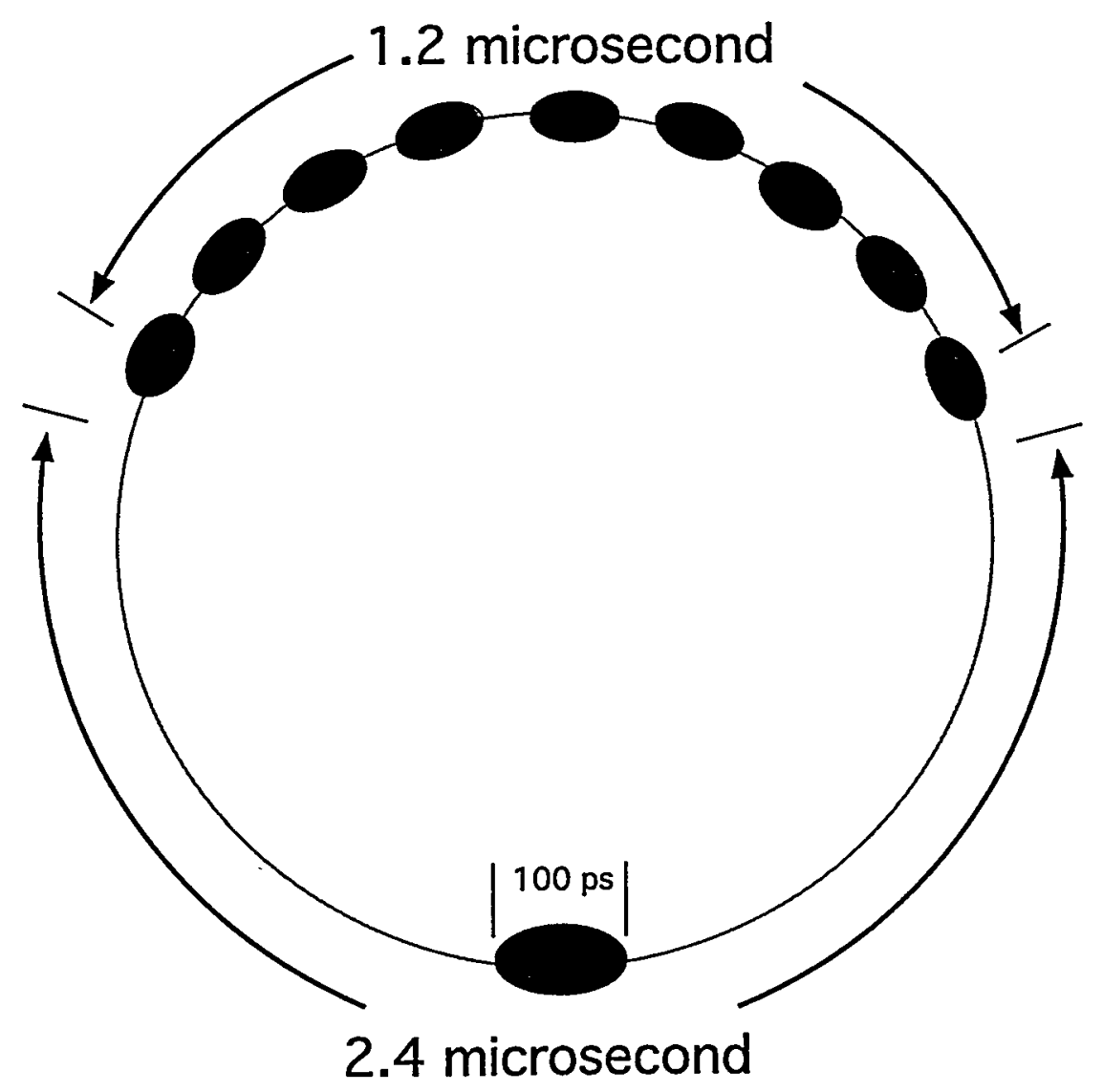

Figure 2. Asymmetric fill pattern for the APS storage ring that would facilitate $100 \mathrm{ps}$ time resolution experiments with this new beam chopper. 
the temporal structure of the APS storage ring. By inserting a Stanford delay generator between the frequency divider and the beam chopper motor controller; the phase between the storage ring temporal structure and the beam chopper rotation can be adjusted to position the transmission time window of the beam chopper on any desired part of the storage ring fill pattern. If an asymmetric fill pattern is used in the APS storage ring, as illustrated in figure 2 , such that only one bucket falls within the transmission time window of the beam chopper, then time resolution as short as $100 \mathrm{ps}$ becomes possible with this new compact beam chopper.

\section{ACKOWLEDGMENTS}

This work is supported by the U. S. Department of Energy, Basic Energy Sciences, Office of Science, under contract \#W-31-109-ENG-38.

\section{REFERENCES}

1. McPherson, A., Wang, J., Lee, P. L., and Mills, D. M., "A New High-Speed Beam Chopper for Time Resolved X-ray Studies", submitted to The Journal of Synchrotron Radiation.

2. The design for the beam chopper is based upon a laser scanner marketed by Speedring Systems, Inc., of Rochester Hills, Michigan. 